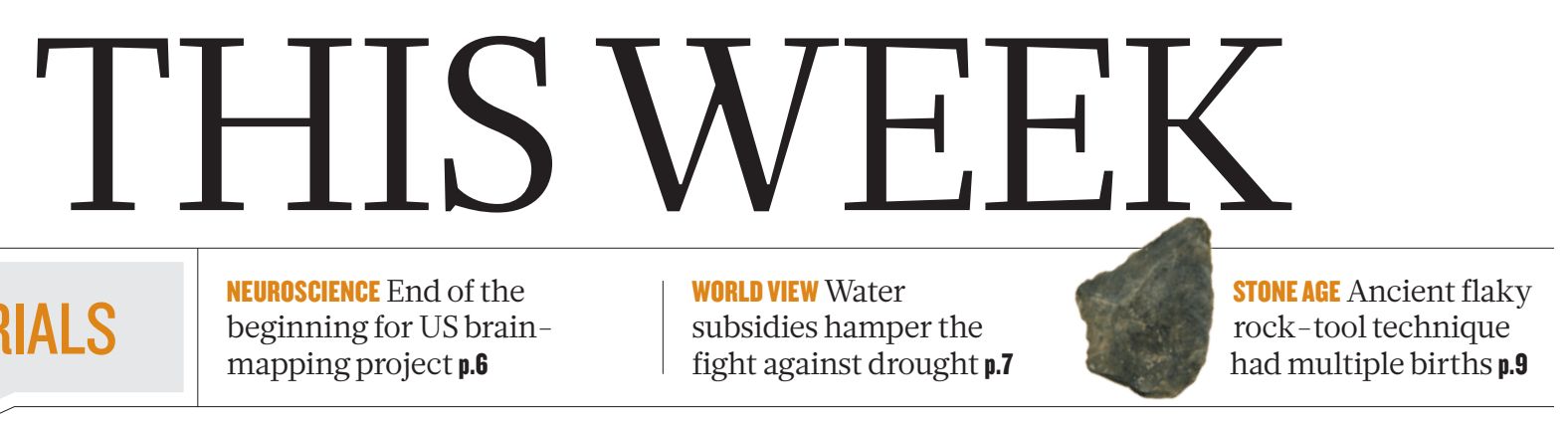

\title{
Retraction challenges
}

Cleaning up the literature can be difficult.

A key responsibility of any journal is to correct erroneous information that it has published, and as quickly as possible.

Easily said! It is straightforward enough for authors to correct a paper. But if it becomes clear after publication that the conclusions are fundamentally flawed, a retraction is appropriate - and things can then get a lot more challenging.

Why, other than through enforcement after misconduct, would anyone retract a paper in a high-profile journal? Regrettably, given the reputational damage that a retraction might yield, it may take a strong code of honour, and a strong consensus among sometimes many co-authors, to go public, rather than just let the paper join the many others that turn out to be flawed and fade away.

That is why the literature of retractions in high-impact journals might be skewed towards misconduct that has been proved through investigations. But all praise to the authors who decide to behave honourably. Where authors make it clear that nothing more than an honest error was involved, their retraction should bring them credit.

Where misconduct - a deliberate attempt to deceive - has been involved, things tend to get complicated. Universities fear misconduct for the immense trouble that it can cause them in investigations, for the legal tussles that can then ensue if the proceedings are contested, and for the potential damage to their reputations. But when such investigations prove misconduct, they often lead to retractions of one or many papers. Even then, if the conclusions are contested, journals might find themselves threatened with a lawsuit for the proposed retraction itself, let alone a retraction whose statement includes any reference to misconduct.

For years, with occasional exceptions, Nature's annual number of research-paper retractions tended to average around one or two. But over the past two years, we have seen a considerable rise - six in 2013, and seven, so far, in 2014. We have reviewed these and previous retractions and would like to make some observations on the basis of their content and on the experiences of publishing them.

A high proportion of Nature's retractions in recent years have come about through honest error, where authors have either discovered mistakes themselves after publication, or have had the errors brought to their attention and taken action.

Another observation is that negotiating some retractions can involve unavoidable delays of years because of some combination of the complexity of the science, disputes between co-authors, the need to await outcomes of lengthy investigations, and disputes over these proceedings. Journal editors have neither the authority nor the means to police authors or their institutions, and can be dependent on proceedings whose details are confidential to institutions. They also need to be sensitive to the interests of blameless co-authors.

Even when an institution and a journal both want a retraction, their interests in doing so may collide. An institution might be bound by confidentiality agreements and therefore unable to release the results of its scientific investigations, leaving editors in the dark as to the

circumstances behind erroneous work. An institution may also wish the wording of the retraction to bolster its case against a wrong-doer, whereas a journal's interest is to avoid lengthy disputes, push the paper into oblivion, and avoid further wasted effort by researchers. Whether for that reason or, occasionally, for legal reasons, we have concluded that we cannot usually use retraction statements as a means of highlighting wrong-doing.

Why the sudden pulse of Nature retractions in 2013 and 2014? (The last year to reach such heights was 2003, when we retracted seven fraudulent papers by the physicist Jan Hendrik Schön.) We can only speculate. The publication dates of the papers retracted in the past two years range from 1994 to 2014. Data are nowadays more openly

"The duty to retract a demonstrably false paper remains paramount." But the concerned should also pay attention to what must be increasing costs in legal fees, because those under investigation increasingly turn to lawyers to defend themselves and their reputations, and their employers and journals are more frequently having to respond accordingly. But whatever the obstacles, the duty to retract a demonstrably false paper remains paramount..

\section{Warming up}

Prospects for international agreement on combating climate change look brighter.

$\mathrm{T}$ There is much for the world to be pessimistic about these days. The double crises of the Ebola outbreak in West Africa and Islamic extremism in the Middle East, for example, pose real dangers. So it says much for the one-day United Nations summit on climate change, held in New York City last week, that not only did it receive widespread media coverage, but also the enduring message sent by the meeting was one of optimism.

There have been enough 'turning points' in the politics of the effort to curb global warming to send anyone dizzy. That is the narrative the story demands: incremental progress is boring; grand gestures are preferred. Every meeting and announcement is the most important, at least since the previous one.

The politics and the science of climate change have long since parted 